\title{
Pregnancy and Cancer
}

\author{
Hideyuki Iwahata, Yuriko Iwahata and Teresa K Woodruff*
}

Department of Obstetrics and Gynecology, Northwestern University, USA

Submission: May 25, 2017; Published: June 05, 2017

*Corresponding author: Teresa K Woodruff, Department of Obstetrics and Gynecology, Northwestern University, USA, Email: tkw@northwestern.edu

\begin{abstract}
Improvement in multimodality treatment has enabled many cancer patients to survive a malignancy. However, these same treatments of cancer can result in gonadal dysfunction and infertility. Especially for patients younger than 39 years of age, there is strong interest in life after cancer treatment including having a partner and siring or having children. This review focuses primarily on the very special case of young female patients who are diagnosed with cancer prior to and during pregnancy. Here we will update obstetricians and gynecologists on the issues that should be considered including what fertility preservation options are available and the existing data on pediatric outcomes after a maternal cancer treatment. More data is necessary to fill in the data and option gaps for patients who face a cancer diagnosis during pregnancy to enable the healthiest outcome possible for the pregnant patient and unborn offspring.
\end{abstract}

Keywords: CAYA; Fertility preservation; Pregnancy management; Contraception

Abbreviations: CAYA: Childhood Adolescent and Young Adult; QOL: Quality of Life; AMH: Anti-Mullerian Hormone

\section{Introduction}

\section{PREGNANCY \& CANCER}
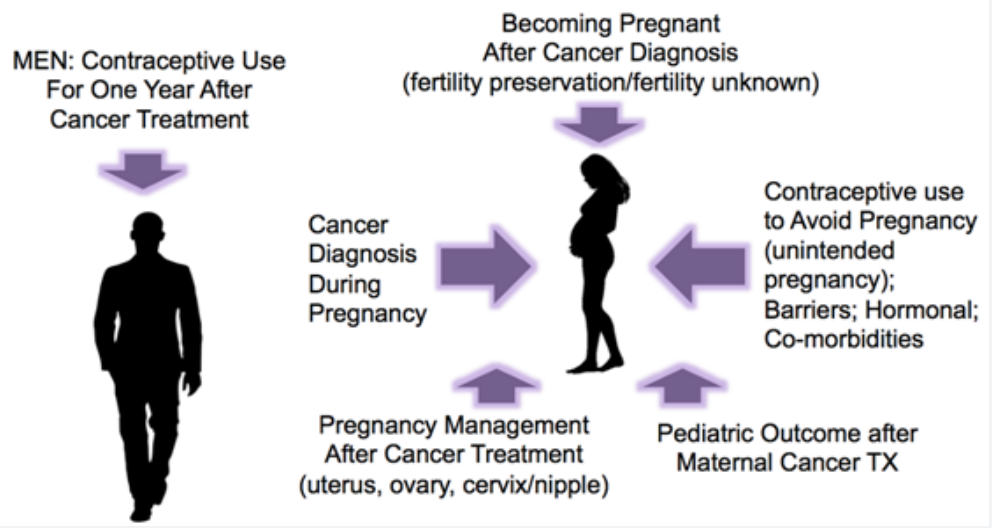

Figure 1: This figure shows the issues associated with avoiding siring or becoming pregnant during cancer treatment for men and women and the additional special concerns associated with a cancer diagnosis during pregnancy in women. For men, the primary issue is associated with the recommendations for siring a pregnancy after completion of gonadotoxic therapy. Generally speaking, males are told to wait for one year to ensure that germ cell development is largely free of mutation risk. If males are likely to be sterilized by treatment, they generally offered sperm banking. The sperm can then be used in assisted reproductive protocols. For females, fertility management is part of the discussion associated with cancer therapy in many cancer centers. Unfortunately, it is difficult to know the fertility status of the patient at the time of diagnosis and the specific amount of fertility loss a patient might experience. That said, there are general guidelines regarding the likelihood of fertility loss and options are available to patients prior to the first cancer treatment. Young cancer patients should be counseled regarding contraceptive (barrier or hormonal) use during and immediately after treatment to avoid unintended pregnancies. A cancer diagnosis during pregnancy is an increasingly more prevalent diagnosis due to the aging of the maternal population. Interventions include termination with aggressive treatment follow-on cancer treatment or delaying cancer treatment to the second or third trimesters if a strategy can be developed that is not associated with embryo toxicity. Women may also opt to wait until delivery to begin treatment. Cancer treatment damage is not limited to the gonads but may involve the uterus, cervix as well as nipple. Thus, cancer survivors should be advised about these potential organ level concerns which impact implantation, the duration of gestation, delivery and lactation. Finally, more data is needed on the health of offspring after treatment for cancer during pregnancy. 


\section{Global Journal of Reproductive Medicine}

Multimodality cancer treatments can affect CAYA patients 'pituitary function, gonads or uterus and cervix and reduce their fertility transiently or permanently [1-3]. The loss of fertility tends to be almost as painful as the confrontation with malignancy itself for young patients who aspire to become pregnant in the future [4,5]. Options for fertility preservation have been improving both experimentally and clinically and at many institutions oncologist are required to provide the accurate information about the fertility threat of the treatment plan, explain the effective options, and refer to reproductive specialists as warranted [6]. This article focuses primarily on the young female prior to and during pregnancy, and aims to provide obstetricians and gynecologists with a summary of how cancer treatment can threaten fertility and adversely affect pregnancy outcomes, what fertility preservation options are available, and the pediatric outcome after cancer treatment (Figure 1). In addition, contraceptive recommendations for men and women will be discussed as a method to reduce unintended pregnancies during cancer treatment (Figure 1).

\section{Becoming Pregnant After a Cancer Diagnosis}

It is important to evaluate the effect of multimodality therapy such as chemotherapy, radiation therapy, and surgery on the ability of an individual to become pregnant [1]. Physicians need to be aware that patients are increasingly interested in fertility management and should be ready to provide options, even in the face of a dynamic pregnancy [1,7]. Factors that influence the reproductive potential of an individual include the age of the patient, type and stage of cancer, drug class and cumulative dose, radiation field, number of treatments, extent of surgical therapy, sex and fertility status before treatment $[8,9]$. Radiation to the brain can affect the hypothalamic-pituitary-gonadal axis $[10,11]$ and chemotherapy and/or radiotherapy can diminish the ovarian reserve. It is difficult to predict if the amenorrhea is transient or permanent and even if menstruation returns, it does not imply the fertile. A low serum level of AMH can be utilized to predict diminished ovarian reserve [12]. There are no studies that suggest chemotherapy treatment increases risk for preterm birth or low birth weight $[13,14]$. Radiation doses of 14-30Gy may impair uterine function and that causes increase of miscarriage, low birth weight, and fetal death $[1,15]$. There are no reports that the risk of recurrence of any type of cancer is increased by pregnancy.

For fertility preservation in women patients with cancer, embryo/oocyte cryopreservation is the most mature technology available. Ovarian tissue cryopreservation is appropriate for women who do not have sufficient time prior to the start of cancer therapy or who are pre-pubertal. At least 86 pregnancies are reported after tissue cryopreservation [16]. Nevertheless, malignant cells may reenter while ovarian tissue is transplanted and the possibility of recurrence may be increased. This method is experimental and should only be offered in a research setting. Other methods to preserve fertility include oophoropexy, which is a surgery to move one or both ovaries to another spot in the body outside the treatment field before radiation therapy to the pelvic region. For male patients with cancer, sperm cryopreservation is the most common method and sperm tissue cryopreservation is experimental. In both sexes, gonadal shielding from radiation therapy can help preserve fertility. Much more information on the options available to cancer patients is provided elsewhere [17].

Tamoxifen is the main adjuvant endocrine therapy for premenopausal patients with estrogen-receptor positive breast cancer. Although it is suggested to administer for 5-10 years [18], oncologists and reproductive endocrinologists sometimes provide a "tamoxifen holiday", being the period with taking off tamoxifen to avoid the side-effect for their fetus, for the patients who want to have a child before completion of tamoxifen therapy. This is a major emerging issue; indeed, in a recent Study, the second most often cited reason for non-initiation or stopping tamoxifen treatment is due to the patients interest in fertility [19]. Having an oncofertility program not only increases awareness of the fertility concerns in the cancer setting, but may also provide assurances to patients that their fertility is preserved for their later use, encouraging them to start and continue the life saving tamoxifen treatment [20]. Previous studies have reported that the mortality rate of completion 5 years of tamoxifen was lower than 1-2years of tamoxifen [21,22]. Since there is no reports to indicate the recurrence rate after the patients take tamoxifen holiday, more research is required to assess the effect.

\section{Cancer Diagnosis During Pregnancy}

Cancer is the second most common cause of death in women during their reproductive years [23] and the incidence of malignancy and pregnancy has increased from 1:2000 in 1964 to $1: 1000$ deliveries in 2000 . The rate of increase is attributed to a delay in child- bearing to the third and fourth decades of life [24]. The most common cancers diagnosed in pregnant women include breast cancer, cervical cancer, Hodgkin's lymphoma, and melanoma. Administration of chemotherapy should be avoided during the first trimester, being the period of organogenesis because the risk for spontaneous abortion, fetal malformations, and fetal death are greatest $[13,25,26]$. A review of 82 articles reported 24 infants (17\%) born with malformations of 139 cases of first-trimester exposure to chemotherapy with single agent. However, this result involved the concomitant use of radiation. The incidence for single agent declines to $6 \%[1,25,27]$. While, the administration of chemotherapy after the first trimester does not result in an increased rate of malformation $[25,27,28]$. During the second and third trimesters, the placenta plays a role as barrier and may protect the fetus from cytotoxic agent in maternal blood [27-29]. This information may prevent termination of pregnancy permitting treatment of disease during a pregnancy [29].

With respect to the cancer itself, a study of 75 pregnant women with breast cancer reported chemotherapy during pregnancy does not worsen the prognosis when compared to 


\section{Global Journal of Reproductive Medicine}

breast cancer in non-pregnant women [30]. Furthermore the safety of chemotherapy after the second trimester is not higher than non-pregnant women with cancer [31]. The effect of surgery may be either diagnostic or therapeutic in the management of malignancy during pregnancy. In general, abdominal surgery is often deferred to the second trimester because the risk of miscarriage is decreased and the size of the uterus still allows a certain degree of access [24,31,32]. Many guidelines and studies advocate avoidance of radiotherapy during pregnancy because it can induce microcephaly, mental retardation, and fetal death $[24,31,33]$. Cancer treatment during pregnancy should be planned with consideration of cancer stage, affect on fetus, and gestational age. Consultation with neonatologists and proper counseling are recommended to better understand the course of pregnancy, feto-neonatal outcomes, and possible complications [31]. A major concern for cancer survivors wanting to get pregnant is the risk of birth defects and the risk of passing their cancer onto their offspring. The affect of childhood cancer treatment on their offspring has been reported and it is suggested that although cancer therapy does not increase congenital anomalies [34-36], it increases preterm birth and low birth weight $[37,38]$.

\section{Contraceptive Use to Avoid Pregnancy}

Many women during or following cancer treatment believe they are infertile. Due to this imprecise recognition, many cancer patients do not use any contraception and if an unintended pregnancy occurs, approximately half of them elect for termination during cancer treatment $[24,39]$. For this reason, women should be counseled that irregular menses or amenorrhea does not always mean that they are infertile [40]. On the other hand, many cancer survivors question the optimal time-point to attempt conception. The general recommendation is waiting two to five years after completion of chemotherapy because that is the time frame when most relapses occur. Some oncologists recommend six months after completion of chemotherapy because it takes about six months for a new cohort of follicles to be recruited for growth and maturation and this timeframe can eliminate any eggs damaged by chemotherapy or radiation. However, these recommendations are largely anecdotal and there is no solid evidence to suggest that postponing conception will alter the outcome of cancer or pregnancy $[1,26]$. Contraception selection for cancer patients depends on the following factors: type of malignancy, disease status (active vs. remission), and other medical comorbidities. Combined hormone contraception should be avoided for hormone dependent malignancy, such as breast cancer, because it can effect prognosis or increase the possibility of recurrence. For patients who are contraindicated from utilizing estrogen therapy, other options include: intrauterine device, barrier, or behavioral methods $[24,40]$.

\section{Conclusion}

This article has reviewed general issues regarding cancer and pregnancy. Importantly, there are many gaps in our knowledge and we recommend that databases of obstetrical outcomes of cancer survivors and surviving offspring be developed. Such a database would enhance the field-wide knowledge of the effects of cancer therapy and the risks on future offspring. Taken together, these understandings will improve the patients' longterm QOL and address one of the most difficult problems facing an emerging group of cancer patients.

\section{Acknowledgement}

The authors thank the editors of the Global Journal of Reproductive Medicine for their invitation to write this short summary of the topic. We acknowledge our funding sources P50 HD076188/HD/NICHD NIH HHS/United States and the Translational Bridge Program of the Robert H. Lurie Comprehensive Cancer Center, Northwestern University (to HI).

\section{References}

1. Kong BY, Skory RM, Woodruff TK (2011) Creating a continuum of care: integrating obstetricians and gynecologists in the care of young cancer patients. Clin Obstet Gynecol 54(4): 619-632.

2. Schmidt R, Richter D, Sender A, Geue K (2016) Motivations for having children after cancer--a systematic review of the literature. Eur J Cancer Care 25(1): 6-17.

3. Levine JM, Kelvin JF, Quinn GP, Gracia CR (2015) Infertility in Reproductive-Age Female Cancer Survivors. Cancer 121(10): 1532-1539.

4. Surbone A, Petrek JA (1997) Childbearing issues in breast carcinoma survivors. Cancer 79(7): 1271-1278.

5. Schover LR (2005) Motivation for parenthood after cancer: a review. J Natl Cancer Inst Monogr (34): 2-5.

6. Woodruff TK, Smith K, Gradishar W (2016) Oncologists' Role in Patient Fertility Care: A Call to Action. JAMA Oncol 2(2): 171-172.

7. Walsh SK, Ginsburg ES, Lehmann LS, Partridge AH (2017) Oncofertility: Fertile Ground for Conflict between Patient Autonomy and Medical Values. Oncologist.

8. Green DM, Kawashima T, Stovall M, Leisenring W, Sklar CA, et al. (2009) Fertility of female survivors of childhood cancer: a report from the childhood cancer survivor study. J Clin Oncol 27(16): 2677-2685.

9. Sklar CA, Mertens AC, Mitby P, Whitton J, Stovall M, et al. (2006) Premature menopause in survivors of childhood cancer: a report from the childhood cancer survivor study. J Natl Cancer Inst 98(13): 890-896.

10. Pfitzer C, Chen CM, Wessel T, Keil T, Sörgel A, et al. (2014) Dynamics of fertility impairment in childhood brain tumoursurvivors. J Cancer Res Clin Oncol 140(10): 1759-1767.

11. Miyoshi Y, Ohta H, Namba N, Tachibana M, Miyamura T, et al. (2013) Low Serum Concentrations of Anti-Müllerian Hormone Are Common in 53 Female Childhood Cancer Survivors. Horm Res Paediatr 79(1): $17-21$.

12. Sabeti RZ (2017) The effect of maternal malignancy on fertility, pregnancy, and neonatal outcomes Lund: Lund University, Faculty of Medicine.

13. Whitton JA, Stovall M, Mertens AC, Donaldson SS, Ruymann FB, et al (2002) Pregnancy outcome of female survivors of childhood cancer: a report from the Childhood Cancer Survivor Study. Am J Obstet Gynecol 187(4): 1070-1080

14. Signorello LB, Mulvihill JJ, Green DM, Munro HM, Stovall M, et al. (2010) Stillbirth and neonatal death in relation to radiation exposure before conception: a retrospective cohort study Lancet 376(9741): 624-630. 


\section{Global Journal of Reproductive Medicine}

15. Jadoul P, Guilmain A, Squifflet J, Luyckx M, Votino R, et al. (2017) Efficacy of ovarian tissue cryopreservation for fertility preservation: lessons learned from 545 cases. Hum Reprod 32(5): 1046-1054.

16. De Vos M, Smitz J, Woodruff TK (2014) Fertility preservation in women with cancer. Lancet 384(9950): 1302-1310.

17. Davies C, Pan H, Godwin J, Gray R, Arriagada R, et al. (2013) Long-term effects of continuing adjuvant tamoxifen to 10 years versus stopping at 5 years after diagnosis of oestrogen receptor-positive breast cancer: ATLAS, a randomised trial. Lancet 381(9869): 805-816.

18. Llarena CN, Estevez LS, Tucker LS, Jeruss SJ (2015) Impact of Fertility Concerns on Tamoxifen Initiation and Persistence. J Natl Cancer Inst 107(10).

19. Vu JV, Llarena NC, Estevez SL, Moravek MB, Jeruss JS (2017) Oncofertility program implementation increases access to fertility preservation options and assisted reproductive procedures for breast cancer patients. J Surg Oncol 115(2): 116-121.

20. Early Breast Cancer Trialists' Collaborative Group (EBCTCG) (2005) Effects of chemotherapy and hormonal therapy for early breast cancer on recurrence and 15-year survival: an overview of the randomised trials. Lancet 365(9472): 1687-1717.

21. Hershman DL, Shao T, Kushi LH, Buono D, Tsai WY, et al. (2011) Early discontinuation and non-adherence to adjuvant hormonal therapy are associated with increased mortality in women with breast cancer Breast Cancer Res Treat 126(2): 529-537.

22. Jemal A, Siegel R, Ward E, Murray T, Xu J, et al. (2007) Cancer statistics 2007. CA Cancer J Clin 57(1): 43-66.

23. Salani R, Billingsley CC, Crafton SM (2014) Cancer and pregnancy: an overview for obstetricians and gynecologists. Am J Obstet Gynecol 211(1): 7-14.

24. Doll DC, Ringenberg QS, Yarbro JW (1988) Management of cancer during pregnancy. Arch Intern Med 148(9): 2058-2064.

25. Peccatori FA, Azim HA, Orecchia R, Hoekstra HJ, Pavlidis N, et al. (2013) Cancer, pregnancy and fertility: ESMO Clinical Practice Guidelines for diagnosis, treatment and follow-up. Ann Oncol 24(Suppl 6): vi160vi170.

26. Arnon J, Meirow D, Lewis-RH, Ornoy A (2001) Genetic and teratogenic effects of cancer treatments on gametes and embryos. Hum Reprod Update 7(4): 394-403.

27. Amant F, Vandenbroucke T, Verheecke M, Fumagalli M, Halaska MJ, et al. (2015) Pediatric Outcome after Maternal Cancer Diagnosed during Pregnancy. N Engl J Med 373(19): 1824-1834.

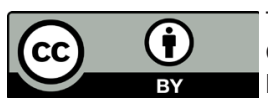

This work is licensed under Creative

Commons Attribution 4.0 Licens

DOI: 10.19080/GJORM.2017.01.555566
28. Amant F, Han SN, Gziri MM, Vandenbroucke T, Verheecke M, et al. (2015) Management of cancer in pregnancy. Best Pract Res Clin Obstet Gynaecol 29(5): 741-753.

29. Litton JK, Warneke CL, Hahn KM, Palla SL, Kuerer HM, et al. (2013) Case control study of women treated with chemotherapy for breast cancer during pregnancy as compared with nonpregnant patients with breast cancer. Oncologist 18(4): 369-376.

30. Amant F, Halaska MJ, Fumagalli M, Dahl SK, Lok C, et al. (2014) Gynecologic cancers in pregnancy: guidelines of a second international consensus meeting. Int J Gynecol Cancer 24(3): 394-403.

31. Duncan PG, Pope WD, Cohen MM, Greer N (1986) Fetal risk of anesthesia and surgery during pregnancy. Anesthesiology 64(6): 790-794.

32. Mazonakis M, Varveris H, Damilakis J, Theoharopoulos N, Gourtsoyiannis N (2003) Radiation dose to conceptus resulting from tangential breast irradiation. Int J Radiat Oncol Biol Phys 55(2): 386-391.

33. Signorello LB, Mulvihill JJ, Green DM, Munro HM, Stovall M, et al. (2012) Congenital anomalies in the children of cancer survivors: a report from the childhood cancer survivor study. J Clin Oncol 230(3): 239-245.

34. Dodds L, Marrett LD, Tomkins DJ, Green B, Sherman G (1993) Case-control study of congenital anomalies in children of cancer patients. BMJ 307(6897): 164-168.

35. Winther JF, Boice JD, Mulvihill JJ, Stovall M, Frederiksen K, et al. (2004) Chromosomal abnormalities among offspring of childhood- cancer survivors in Denmark: a population-based study. Am J Hum Genet 74(6): 1282-1285.

36. Madanat-Harjuoja LM, Malila N, Lähteenmäki PM, Boice JD, Gissler M, et al. (2010) Preterm delivery among female survivors of childhood, adolescent and young adulthood cancer. Int J Cancer 127(7): 16691679 .

37. Haggar FA, Pereira G, Preen D, Holman CD, Einarsdottir K (2014) Adverse obstetric and perinatal outcomes following treatment of adolescent and young adult cancer: a population-based cohort study. PLoS One 9(12): e113292.

38. Patel A, Sreedevi M, Malapati R, Sutaria R, Schoenhage MB, et al. (2009) Reproductive health assessment for women with cancer: a pilot study. Am J Obstet Gynecol 201(2): 191. e1-4

39. Patel A, Schwarz EB Society of Family Planning (2012) Cancer and contraception. Contraception 86(3): 191-198.

40. Patel A, Schwarz EB, Society of Family Planning (2012) Cancer and contraception. Contraception 86(3): 191-198.

\section{Your next submission with Juniper Publishers} will reach you the below assets

- Quality Editorial service

- Swift Peer Review

- Reprints availability

- E-prints Service

- Manuscript Podcast for convenient understanding

- Global attainment for your research

- Manuscript accessibility in different formats

( Pdf, E-pub, Full Text, Audio)

- Unceasing customer service

Track the below URL for one-step submission https://juniperpublishers.com/online-submission.php 